\title{
EXPLORING THE POLITICS OF LOCAL PARTICIPATION IN RURAL DEVELOPMENT PROJECTS: SMALL DAMS REHABILITATION PROJECT IN ZIMBABWE
}

\author{
Jacob Tagarirofa, Bernard Chazovachii, Researchers \\ Great Zimbabwe University, Zimbabwe \\ E-mail: bchazovachii@gmail.com
}

\begin{abstract}
The study sought to evaluate the effectiveness of community participation in rural development projects in Zimbabwe testing the credibility of the popularized supposition that almost all contemporary development efforts characteristically embrace local participation. Public participation is widely assumed to be an essential ingredient for the fruition of rural development efforts. The research made use of quantitative and qualitative research methodologies in which unstructured interviews, focus group discussions and questionnaires were used as data gathering instruments. The analysis of data was enabled by the use of People-Centered Development (PCD) as a conceptual framework. Findings revealed that the level of community participation in the district is not only minimal, but it is also top down. This has much to do with the negative perceptions by facilitating agents viewing local people as passive recipients of externally crafted models of development and other factors such as the power dynamics within and between the community and other stakeholders. The research also found preferential treatment of other tribal groups by the facilitating agent, intra group conflicts and bureaucratic and political influence as obstacles militating against effective participation. Based on these findings, and consistent with the wider literature, recommendation are that the nature of community engagement should be based on the principle of equal partnership among all stakeholders as this would encourage full cooperation and thus effective participation.
\end{abstract}

\section{KEY WORDS}

Politics; Local participation; Sustainable rural development; Rehabilitation; Projects.

Provision of adequate and safe water to both rural and urban inhabitants remains a challenge for most developing countries, Zimbabwe included (IUCN,2005). Government and donor efforts to address challenges associated with water shortages appear to be inadequate due to several factors key among them being lack of participation. This subject is of critical importance given that an estimated $70 \%$ of Zimbabweans live in rural areas and their livelihoods are closely linked to access, use and management of water resources (IUCN, 2005). Despite the centrality of water in rural people's productivity, direct users of the resource remain peripheral in decision-making processes, especially at the planning and management levels (Agrawal, 1991; Fortmann and Nabane, 1992). The research is premised on the understanding that the concept of community participation as widely advocated for by the participatory development paradigm has not lived up to its billing of ensuring the practical and meaningful involvement of the local people in development projects in rural communities.

It is clear from evidence in the literature that the concept has not brought the results expected of it due to marginalization of intended beneficiaries from partaking. In fact, community participation has been largely rhetorical and has remained elusive in the realm of practice in rural development projects. Notwithstanding its theoretical popularity in the discourse of participatory development, the concept has been over-rated and oversold by development agents and governments in developing countries. These have fallen into the trap of taking the phrase participatory development at face value yet in pragmatic terms it has grossly been deficient in project implementation. What is even more salient is the realization that, community participation exercises are gradually and explicitly degenerating into distanced undertakings where ordinary people have mostly become recipients of predesigned programmes, often a product of administrative manipulation. It would seem to mean that development agents are determined to impose their own version and understanding of community participation on particular communities (Brohman, 1996: 34). 
Therefore, it is against such a setup that the research sought to evaluate the effectiveness of community participation in rural development projects in Zimbabwe testing the credibility of the popularized supposition that almost all contemporary development efforts characteristically embrace local participation. The study sought to review community participation with the view to suggest specific remedies to inform more meaningful forms of engagement, dialogue and empowerment at local level. The research, therefore, evaluate whether the nature of community engagement in Mushagashe community is promotive of local participation and suggest numerous conceptual and practical steps that development agents and the local people should adhere to if otherwise, for the institutionalization of effective involvement of local people in development initiative.

Significance of the study. Wilcox (1996) had noted that although the concept of community participation has virtually moved to mainstream development since the mid1980 s, many attempts at institutionalizing community participation have been characterized by partial success, because development practitioners are often unclear about where and which level of participation is feasible. However, suffice it to say that bringing communities to 'talk about a community project is necessary, but not sufficient for communities to realize project gains (Kottack, 1998: 67). Therefore, participation is most likely to be effective when the different interests groups in a project are satisfied with the level at which they are involved. This will then be useful to ascertain conditions that might promote or inhibit communities from attaining the full benefits of participation. The findings and recommendations could be used in rural development planning and implementation of rural development strategies. This particular research would be helpful in casting light on the nature of participation in this particularly community. This would ascertain whether the participation is active or passive, direct or indirect and voluntary or coerced. Besides, the research would also bear a positive effect in enlightening the community of its need to be directly part of activities that affect its wellbeing in the long run. It would also appraise the scant studies of community participation which have previously focused on the impact of participation on the overall project outcome and overlooking the need to ascertain whether there is that participation in the first place. As a consequence, this could be a positive point of departure for any endeavors to influence the nature of community engagement towards a more participatory orientation.

Conceptual framework. The concept of community participation in development gained prominence in development discourse in the 1970s and since then literature on the subject has grown significantly (Chambers, 1992; Oakley, 1992, Brohman, 1996). According to Winder (1981:13), it was through the influence of Paolo Freire's work on the concept of conscientisation and analysis of the structural obstacles to the development of Latin American peasantry which stressed the dialogical approach to project work. His argument was that the peasant should be the subject and not the object of development, and this orientation helped affirm the importance of participation. Notably, Catanese (1984:124) reiterated that the idea of community participation in planning had been a long standing and intrinsic part of the history of planning. Thus this words 'participation' and 'participatory' development (Rahnema, 1997:117) appeared for the first time in the development jargon during the late 1950s, Stiefel and Wolfe (1994:21) hold that the term popular participation entered into the international discourse on development during the 1960 s and became most prevalent in the 1970s, especially in respect of the field of rural development.

Thus at this time local participation became a major concern for United Nations agencies such as International Labor Organization (ILO); the World Health Organization (WHO); the Food and Agricultural Organization (FAO); the International Fund for Agricultural Development (IFAD); and the United Nations Educational, Scientific and Cultural Organization (UNESCO) (Oakley and Marsden, 1994:14). For example, the FAO identified participation as central to future strategies to tackle rural underdevelopment and more specifically, to realize the success of the Small Farmer Development Programme (SFDP) in Nepal launched in 1980, which included the People's Participation Programme (PPP) (BorteiDoku, 1991:61). Since then, many resources have gone into the promotion of participation in rural development. Participation seemed to gain ground again in the 1990s with the hopes 
that it would emancipate people from the bedeviling crises of their collapsing livelihoods (Maser, 1997:12).

This revival was marked by the International Conference on Popular Participation in the Recovery and Development Process in Africa which was held in Arusha, Tanzania in 1990. In the opening statement, of this conference, Adedeji was quoted as saying: "The democratization of the development process, by which we mean the empowerment of the people, their involvement in decision making, in implementation and monitoring process is a condition sine qua non for socio-economic recovery and transformation. African leadership and African people must not desire self reliance but must will it" (Shaw, 1990:20).

The incorporation of the local people in development projects has become a common phenomenon which almost every organization claims to embrace. However, this acknowledgement seems biased since it has not been the case with 'every' organization. For instance, at a macro level, the Economic Structural Adjustment Program (ESAP) for most developing countries was alleged by Kanyenze (2004:106) to be a mere imposition by the World Bank and International Monetary Fund which was deficient of local input hence their failure. The concept originated after it was realized that the top-down approach to development did not achieve its developmental goals, which were often very specific material outcomes, and this in turn may have been linked to the lack of inclusion of those people for whom these outcomes were designed (Brohman, 1996). This can be exemplified by the USAID case which Chiome and Gambahaya (2000) revealed as a clear illustration of the negative effects of the domineering role of development agents. In this context it constructed pit latrine toilets in a Bangladesh community without consultations and consent from the local community with the intention of preventing what the implementing agent foresaw as a potential hub for disease outbreak since the community used to defecate in their rice fields. These efforts by the agent were futile since they were met with violent resistance from the community, which responded by destroying the toilets arguing that it was their cultural practice to use their rice fields as toilets for the sake of increasing productivity. In this context the agent did not consult the community in the first place and this is why the community did not take part and instead destroyed the constructed structures in protestation.

Therefore, the current development efforts have been recommended to embrace local or community participation if they are to depart from repetition of the domineering and exclusivist orientation that characterized past development approaches and their negative effects. However, even though the discourse on participation has been widely accepted and emphasized as a feasible substitute for the unwarranted relegation of the local people in implementation of development initiatives, the rapid proliferation of the term and its myriad applications have sparked a great deal of debate and controversy (Chambers, 1992; Brohman; 1996). Consequently this served as a stimulus for more critical enquiry of the concept in the contemporary epoch as is the preoccupation of this particular paper.

Furthermore, despite its wide acceptance as a useful approach to rural development, Makumbe (1998) submits that its proclamation has been more rhetorical than it has been practical in as much as there have been overwhelming evidence of limited cooperation from local people due to their marginalization from participation in its proper sense, a case in point is the Bangladesh case alluded to by Chiome and Gambahaya (2000) above. As such, the concept of community participation has remained a key theme in development discourse for the past few decades, yet a variety of literature alleges that there is no significant transformation from development agents' notions of the local people as passive recipients of predesigned development projects (Makumbe, 1998; Kanyenze, 2004).

During the preceding decades, African countries and many others in the developing world have witnessed an unparalleled surge in programs and projects aimed at providing solutions to development woes that have been troubling them (Howard, 1998). Conversely, these efforts have remained in vain since they have left out the 'victims' in the identification, planning, implementation, monitoring and evaluation of projects aimed at averting their fate (Kottack, 2001). Coetzee (2001) further notes that this logjam has precipitated from the failure of these programs to include analyses of social and cultural phenomena, which influence the relationship between people and development. Awori (1996:1) have noted that, 
fundamentally lacking in these approaches has been the peoples' dimension which incorporates their indigenous knowledge, experiences, technologies, aspirations, skills, wisdom, culture and local governance systems. This is best explained by the reasons why USAID failed in Bangladesh and ESAP failed in most developing countries as alluded to above by Chiome and Gambahaya (2000) and Kanyenze (2004). A classical example is the recent findings by Gukurume and Nhodo (2010) on the participation of the local people in CARE's Conservation Farming Project in Chivi district of Masvingo in Zimbabwe. They established that the failure of the project in some areas such as Maringire and Mhandamabwe was highly due to the imposition of the project without grassroots consultation from the onset which later thwarted efforts to mobilize the communities for participation.

Coetzee (2001: 87) confirms that these bygone approaches to development were heavily influenced by the models of 'dependency' and 'intervention' based on rescue solutions in times of crises and emergencies. This was the preoccupation of the modernization paradigm which emerged as a consequent of the Marshal Plan which was aimed at resuscitating war ravaged Europe after the World War II (Brohman 1996). Development efforts were often prescriptive and dictated to the people what organizations thought the people's problem was, and how to solve it. Put differently, the United Nations development Program (UNDP) (1998:7) has written that, organizations prescribed to the people the 'song' that they wanted them to 'dance' to, rather than 'dancing' with the people to the 'song' that the people had chosen. In this scenario, the people were viewed as passive recipients of development policies and programs rather than active participants in the process. The people were dependent on the government and development agencies for solutions to their problems. The general belief was that the people did not have the knowledge to change their own lives, leaving governments, policy planners and experts in development issues to decide for them (Kottack, 1996:12). Governments and development agencies had for decades, adopted this approach, and solved crises as they arose rather than developing long-term programs involving the people.

The people for whom these policies were designed were generally marginalized and ignored since they were not given the opportunity to initiate, design and plan development projects that were ultimately expected to help them (Kottack, 1996; Makumbe, 1998; Brohman, 1996). In most cases, the people were expected to take over the project in the implementation phase (Gukurume et.al, 2010). The researcher opines that, this approach gave the impression that people, especially rural communities, were not qualified to initiate, design or plan projects or programs. Furthermore, Makumbe (1998) and Gukurume and Nhodo (2010) concur that the development arena was dominated by governments and foreign experts, mostly male. Groups such as women, local based organizations, local people, especially rural communities, were marginalized in the development process. The gender dimension of poverty was overlooked although, according to the UNDP, women represented and still represent the majority of people living in poverty all over the world. Similarly, local skills, talents and experience were underestimated. As such, the government and foreign experts did not understand the real needs of the communities since they did not stay among the people or make an effort to involve them in the choice of development programs.

As a result, most of the efforts by both governments and development agencies failed to have any lasting impact on the real life situation of the people. In most cases, the development programs that the people were expected to take over in the implementation phase collapsed; communities did own programs and projects that were imposed on them and did not feel responsibility for their failure or success. However, in since 1990s there has been a shift by governments and development agencies in policy and focus in the attainment of sustainable rural development programs. These have claimed to be using a participatory approach to development in project implementation where the community is allowed free play in the development process, that is, from the design, implementation and the monitoring and evaluation stages as Makumbe (1998) confirms. Nonetheless, in as much as the above is true in the view of governments and development agencies, the facts on the ground 
suggest that the participation has not been that meaningful. As such, questions have been posed as to whether current government and donor driven development efforts are indeed informed by community participation or rather the concept is a mere formality which has corrupted its prominence in the broader development horizon.

Thus Matowanyika (1998:11) attests that "... in the history of failed development efforts in Lesotho and the region, a major fault is that development programs were not rooted in local values, institutions and local people's committed responses". Therefore, it is precisely due to this background of failed development that this applied research seeks to unearth the weaknesses of past and current development efforts in their unwarranted disregard of the much needed involvement of the local people in all the phases of development projects.

This research will be informed by the People Centered Development (PCD) paradigm as propounded by Chambers (1992). Its point of departure is the assumption that society is shrouded in suffering and oppression (Muther, 2004). Thus the goal of this theory is to 'free' the communities from the cradles of domination and oppression. By being dominated and oppressed, the communities are not able to participate in development projects; a situation which is obtaining in current development endeavors (Kottack, 2001; Gukurume and Nhodo, 2010). As such, this perspective questions whether past and current practices address social justice and empowerment. It is from this background that this research proceeded from within this theoretical framework since the theory explicitly demonstrates commitment to the full realization of effective community involvement in any development efforts aimed at improving the living conditions of the community.

\section{RESEARCH METHODOLOGY}

The research used both qualitative and quantitative research methodologies. A combination of these two methodologies was suitable for this research because they helped in soliciting full, in-depth accounts of the levels of participation of the local people as statistically reflected in the records and reports of this project and their perceptions. This complementary usage of this design helps in the acquisition of comprehensive data about the variables under investigation. A combination of merits of the designs implies that the demerits of each can be eliminated by the advantages of the other. Combining these two methodologies obviously yields added advantage to the reliability of the findings if proper data collection tools are employed, relative to using a single research design. Quantitative methods were used to measure variables that were linked to the research problem in the case study area. The rationale behind using qualitative methodologies, in addition to quantitative data, was to increase understanding about dynamics, opinions and perceptions of people in the case study area about the efficacy of their participation in local project aimed to benefit them. A literature review; questionnaires, informal and semi-structured interviews and focus group discussions were used as data collection tools in the research process. Simple random sampling and purposive sampling was used in gathering data from the population of the area. The research used content analysis and descriptive statistics in the presentation and analysis of that data.

\section{RESULTS AND DISCUSSION}

Community Perceptions. Participation has been conceptualized as an active process in which the participants take initiatives and take action that is stimulated by their own thinking and deliberation and over which they can exert effective control (Rahman 1993: 54). However, this is one but among several definitions by different scholars. From a community's point of view it was established that effective community participation is when the locals who in this case are the raison d'être of projects in communities are actively participating, that is, from the birth of the idea to the design stage, implementation, monitoring and evaluation stages as well as benefit sharing where necessary, through for instance making decisions, as confirmed by a significant proportion of the respondents in the focus group discussions. The majority, $92 \%$ of the respondents, men and women, the young and the old 
were in concurrence with the view that their genuine participation in developmental projects in their respective localities should be a prima facie consideration if community participation is to be institutionalized and effectively operationalized in development projects.

This concurs with Cernea's (1994:54) acknowledgment that, "...putting people first in development projects is not just about organizing people but it means empowering them to be social actors rather than passive subjects and take control over the activities that affect their lives". This admission seems tenable if one considers the fact that these are the same theoretical sentiments behind the People-Centered Approach to development's emphasis on the need to depart from the repetition of the dictatorial and exclusivist orientation that characterized past development paradigms such as the modernization theory, and embrace and value the contribution of the local people in the first place as attested by Brohman (1996). This participatory orientation seem to precipitate from the realization of the negative ramifications of excluding the local people in any development endeavor in which they are either beneficiaries or victims, a deliberation which accounts for why for example other respondents were quick to say that, "Organizations are not sincere and that they preach participation on paper yet in practical terms it is inexistent". Another young woman said that,

"...if the development project is for us why then exclude us from the proceedings?"

These sentiments are in tandem with Kottack's (1996:24) acknowledgement of the need to put the local people at the heart of any development effort when he emphasizes that this should be informed by the idea of "...nothing for them without them". Consequently, the research established that the community perceives their participation in development projects as an important element if they are to establish feelings of ownership towards any development efforts which directly or indirectly affect them both in the short and long run. "Beneficiary participation in project life cycle is of paramount importance for the realization of sustainable projects" so said an elder in the village.

Indeed any development initiative that excludes or belittles the locals in terms of participation is an antithesis to efforts towards institutionalizing community participation as a fundamental element in ensuring sustainability in projects. This view is also substantiated by Berrenman, (1994:6) who affirms that, "the concept of indigenous development per ser envisages a perspective in which people living in a specific social, cultural, economic and ecological setting define their own concept of development, definition of relevance and that correspond to indigenous circumstances". This observation concurs with the participatory approaches' pre-occupation with the need to root any development efforts in the hands of the intended beneficiaries if the positive attributes of invoking participation in the first place are not to remain a mirage. This view is complementary to Brown's (2000) postulation that, community participation is the active process by which beneficiaries influence the direction and the execution of the whole project cycle rather than merely being consulted or receiving the share of benefits. This automatically implies that, participation should be from project identification to evaluation rather than assuming its existence merely because of the prevalence of such words as 'consultation' and 'community involvement' in the documents of the implementing agents.

Organizational Perceptions. A review of the terms of reference and programme activities against the findings from the field proved that development agents only profess community participation on paper through the terminology which is not only deceiving in its disregard of the absence of such participation by the local people on the actual ground, but, demonstrates how they are still erroneously engulfed in perceptions of the local people as incapable of effectively and positively partaking in development projects since they are perceived to be lacking the necessary technical know-how associated with project management, which they considered a prerogative of the trained project managers. One employee from Care was not hesitant to confess that, "...the truth is that, these people should be mere spectators in our executions because in most cases they need to be taught a lot of staff before we begin any project which in turn is wastage of time since we can just make the project functional for them without them".

The research notes that the organization's terminology in the terms of reference which for example use such words like 'involvement', 'consultation' and so forth in their 
methodology of engagement towards community participation, is deceiving in as much as it depicts high levels of the organization's interaction with the community in the project. This can be further supported by the visible variations in terms of the participants' responses to their involvement in various stages of the project. For example, identification was $100 \%$, but other stages such as planning, implementation and monitoring and evaluation were $45 \%$, $70 \%$ and $25 \%$ respectively. This variability is a valid indication of the absence of broad based consultation at all stages of the project.

It is also reminiscent of Arnstein's ladder of participation in which the initial stage of the project is equated to 'manipulation' which is categorized as 'non-participation' (Arnstein, 1969). This implies that the implementing agent would manipulate the process to appear as if the local people are participating yet in actual fact it is non-participation. This perception seems to be the reason behind the emergence of the People-Centered Development Paradigm, which Chambers (1998) alternatively refers to as "Putting the Last First", a loaded phrase which connotes the inclusion of the marginalized at the heart of development efforts regardless of what they know or do not know. This observation tallies with Makumbe's (1998) assertion that, development agent's proclamation and understanding of community participation has been more rhetorical than it has been practical inasmuch as there have been overwhelming evidence of limited cooperation from local due to their relegation from participation in its proper sense. The irony is visible in the controversial and subjective responses given by some of Care's field officers. For example another officer from the NGO commented that, "...community participation is the involvement of community members in project formulation, monitoring and evaluation".

As a consequent of these variances in perceptions and view points, current accounts of participation suffer from a lack of understanding and what it intends to attain. Such a situation further mystifies and romanticizes the concept of participation, making practical application even more problematic. Nevertheless, in spite of such gross variances in perceptions on community participation, the concept has remained vague and obscure in its continuous lack of practical implications. Muther (2004) states that, due to the relative ease with which most NGOs approach participation, the concept has suffered all, from abuse to casual transformations and rendering of its true meaning. As a result, participation has been misunderstood to suggest mere coming together of stakeholders, which is distorted as meaning consultation. The general belief from respondents therefore was that community participation includes, but is not limited to meetings, consultations and events. Respondents from focus group discussions remarked that community participation involves actions from both development agents and target communities that seek to achieve willful partaking or involvement in a project. It was thus established that the coining of development models by development agents was in a way influencing on how the communities should organize themselves in project implementation. Therefore it would seem to mean that NGOs are imposing their will on communities when it comes to project implementation.

Mechanisms to promote participation. There are four strategies of encouraging participation in rural development projects as outlined by Oakley and Marsden (1998:23) and Muther (2004). Firstly they claim that collaboration of beneficiaries is sought by informing them of the rural development plans. This, they argue would be the starting point for everyone who is willing to participate in that they depart from the same spring board and they can move at the same wave length. On the contrary this was not the case as respondents in semi structured interviews confirmed that "...the development agent only planned alone and later on informed the Village Development Committee (VIDCO) through the RDC of the plans". This implies that participation was 'top-down' since it came straight from the development agent to the VIDCO via the RDC and then finally to the community. This contradicts the People Centered development Approach's call for the need to include all stakeholders, especially the beneficiaries in the identification, planning, implementation and monitoring and evaluation of development projects as Maser (1998) confirms.

This is further strengthened by Oakley (1992) who recognizes community organization as a prima facie basis for effectively promoting participation. The World Conference on Agrarian Reform and Rural Development (WCARRD) declares that active community 
participation can only be achieved adequately organizing the people at local level. As such the reason for passive participation in this particular project could highly be attributed to lack of effective organization of the people at the local people since the local institution of leadership was ridden with problems of administrative capability and legitimacy. This is because as shown earlier, respondents were quick to accuse the VIDCO of using political power to force people to participate. For instance one community member had to exclaim that, "...the vidco is all Zanu PF, what you would expect is to follow what they want because if you don't they will deal with you individually". This typical organization is contrary to the one envisaged by the WCARRD and therefore would not equally effect positive participation.

One of the main activities of this project was community mobilization and maximum community participation since it was said to be a community based project. This was done in different activities such as empowerment of local leadership structures, and community capacity building through education and training as identified before. This seems to have been based on the project's major objective which was stated as "To develop an effective and appropriate methodology to initiate and implement (by community), mechanical and biological rehabilitation of small dam in Mushagashe. This demonstrates the implementing agent's commitment to ensuring the massive involvement of the community in efforts towards achieving the stated objective. It shows that the community was expected to be at the fore of 'initiating' and 'implementing' whatever was necessary for the fruition of the project. This seemed as if the community was to partake in the whole project cycle.

Nevertheless, this seeming commitment emerged to be theoretical than it would be practical if cross-examined against the findings. The research confirmed and affirmed Chambers (1992) and Cordillo's (2001) observation that, much of literature on community participation is project documentation by international and local NGOs on particular projects they support, which does not reflect the real activities on the ground. My argument is that, they just purport the prevalence of such participation on paper as a matter of record to appease their donors such that they secure long term funding. This assumption is based on the absence of a genuine reason by the NGO for not ensuring that what they write as their programme objectives and activities inform what happens on the ground. This was also solidified by respondents from semi-structured interviews who happened to be representatives of Care; one field officer Julius confessed that, "...we just draft these programmes without due input of the local people because it serves no purpose to consult them on project proposals on which they are logistically unknowledgeable of'. Another one stated that, "...yes we do value community participation, but for things to move on it's not always the case that these local people should take part, it is not feasible".

The researcher opines that, these sentiments are just but a mere reflection of the extent to which it is a vivid and valid to allege that NGOs are hypocritical in their undertakings in that, on paper they claim to establish mechanisms that support positive and effective community engagement yet on the ground the playbook changes. This does not only replicate the modernization theory's prescriptive orientation and its rigidity in its disregard of the knowledge of the indigenes, but, also concretizes the possibility that these NGOs concentrate more on their role in ensuring successful community participation and ultimately overstate the case.

Community Participation in Project Phases. Beneficiary participation in project life cycle is of paramount importance for the realization of sustainable projects so said a councilor in the village. Indeed any development initiative that excludes or belittles the locals in terms of participation is an antithesis to efforts towards institutionalizing community participation as a fundamental element in ensuring sustainability in projects. This establishment is also substantiated by Berrenman, (1994:6) who affirms that, "...the concept of indigenous development per ser envisages a perspective in which people living in a specific social, cultural, economic and ecological settings define their own concept of development, definition of relevance and that correspond to indigenous circumstances".

This view is complementary to Brown's (2000) postulation that, community participation is the active process by which beneficiaries influence the direction and the execution of the project cycle rather than merely being consulted or receiving the share of benefits. This 
automatically implies that, participation should be from project identification, design, implementation and monitoring and evaluation rather than assuming its existence merely because of the prevalence of such words as 'consultation' and 'community involvement' in the documents of the implementing agents.

The responses to this matter are supportive of the above idea. Of the household questionnaire respondents, $100 \%$ concurred that they were consulted in the identification but the subsequent stages the participants were significantly low insofar as there were no other reasons for the reduction in participants. In the planning stage only $45 \%$ of the respondents were part of the activity whilst only $75 \%$ of the respondents partook in implementation. Only $25 \%$ were involved in monitoring and evaluation. This variation is indicative of effects of the interplay of such factors as political influence, intra group conflicts in the form of tribalism and elite manipulation. perhaps suggesting that participation was top-down since in most technical stages such as monitoring and evaluation and planning, the community was not fully cooperating yet the stages proceeded without them implying that, there could be other technocrats who were partaking without bothering much of the absence of the community. As such, indeed effective participation remains an elusive admiration especially if the community is not active in every crucial stage of the project which in turn enhances a strong sense of ownership of the project as Eade (2000) observes.

The influence of Local Leadership on Community Participation. The research established that NGOs only recognize the local leadership structure as a matter of principle or for the purpose of satisfying the protocols and not as a fundamental obligation. Some of the VIDCO members, concurred in their view that, "...these local NGOs just come to them for signatures from these leaders such that they use them to authenticate their claims that they have consulted the communities in question and just for filing and records purposes".

Technically this implies that the implementing agent wields more power even to control and subvert the local leadership. This is confirmed by some of the members, who complained that, "...we are just used when it comes to mobilizing the communities only yet we were not part of the planning. So usually we would pretend as knowing but we will be ignorant of what comes next".

This observation qualifies Cooke and Kothari's (2001) view that participation has been misconstrued by many, with the effect of creating false illusions of local community involvement and empowerment while at the same time reinforcing norms and existing power relations between the local people and implementing agents. The writer notes that this oversight clearly refutes the general participatory development notion that community participation automatically empowers the community to make decisions on issues that affect them (Chambers, 1992). From the above analysis, it appears so that decision making control by communities is only held as a formality and never in reality. As such, the project activities and methodology exhibited gross disregard of power structures at the micro-level and paradoxically, to concentrate on the local would also exacerbate prevailing inequalities especially if Kottack's (1996) postulation that, the production and representation of knowledge is totally different from the exercise of power, is considered.

It is apparent therefore that, any development efforts which disregard the local leadership structures are likely to have problems in effectively mobilizing the local people to fully cooperate. This is primarily because; these local structures are symptomatic of the local peoples' popular will especially if the structures are a product of democratic deliberations. It follows logically as well that, any undemocratic leadership structure is bound to be less progressive in terms of mobilizing the community to be cooperative in due to the community's resentment emanating from general disregard of illegitimate authority. This is consolidated by Makumbe (1998:87) who argues that, "such legitimation crisis fosters hostility from the community which finds no basis for recognizing clandestinely 'elected' people". This simply implies that, in any development endeavor, it is essential to ensure that the inherent power dynamics does militate against the primary objective of the development project, which is empowerment, through creating unnecessary tensions that will ultimately culminate in apathy. Hence, the People-Centered Development approach envisages a situation in which 
local institutions are supposed to be put at the fore of development if the indigenes are to feel ownership of the project (Mason and McNulty, 2000).

\section{Challenges to Community Participation.}

Domineering Development Agent. This is when the development facilitator or agent is dictatorial and does not celebrate the variability of ideas from the other stakeholders, particularly the grassroots. Chiome and Gambahaya (2000) argue that, the disregard of contributions by the local people has resulted in the failure of many community development initiatives. Their argument is premised on the need to recognize the positive ramifications of indigenous knowledge from the local people, an understanding of their needs from their perspective. The research has established that the development agent was very dominant in all phases of the project cycle, not even giving the local people any opportunity to fully participate in other phases of the project. For example, identification stage seems to be the most popular stage in the project cycle in which almost everyone participated. Varying proportions of the respondents were active in planning, implementation and monitoring and evaluation stages. Suggestively, this reinforces the view that development projects are initiated by outsiders instead of the insiders (Kottack, 1996). The insiders are only used to ratify what has already been designed so that it would appear as community consent. This however is done in a very cleverly fashion where the facilitating agent use some of the locals especially the learned ones who may have been out of touch with the realities in the community since they view themselves as distinct from the rest and look down upon the poor in the community (Kaufman and Alfonso, 1997). They further note that the views of these elite groups in the community are then processed as direct views of the community. Such a situation is very detrimental in that it culminates in notions of full cooperation by the whole community yet it is just an individual. One participant at a focus group discussion remarked that, "Organizations arrived already knowing everything. They come here and look around but they see only what is not here. They appoint their own teams to carry out what they call 'baseline surveys' and information from these survey s becomes community consent".

The above argument is depictive of a unilateral situation whereby community consent is manufactured and becomes bait for sourcing funds from funding organizations. It was also established that, often, the so-called professional experts dominate decision making and manipulate instead of facilitating development processes. This can be substantiated by one household respondent to the interview, who insisted that, "...the Care officials told us at one point that, if we have any problems with the project we should just excuse ourselves since he can make it work alone".

It is common knowledge that the trademark of 'development experts' is often that they always know best and therefore, their prime function is to transfer knowledge to the communities whom they view as 'knowing less' (Kaufman and Alfonso, 1997). This vividly demonstrates that the nature of participation in this context is top-down rather than bottom up. Given such a situation it would be naïve to accept the view that the current discourse on community participation is genuine in its attempt to empower communities to choose development options freely, but should rather be accepted as an attempt to sell preconceived proposals for the betterment of organizational aspirations.

Unequal partnership. Dennis (1997) alludes that, this is the recognition of the importance of every person's skill, ability and initiative and that everyone has an equal right to participate in any processes irrespective of their status. The researcher notes that, this depicts a departure from imposition of development projects by those supposed to facilitate, to a two way process where the grassroots' contributions should not be overlooked at face value since they should as well inform the subsequent processes. This therefore, perhaps, is a justification for the need to even factor in indigenous knowledge in community development processes, a deliberation which discards the modernization theory's lament for the revocation and replacement of traditional cultures with modern culture and models of knowledge. Development processes should be sensitive to variability in knowledge as Coetzee (2001) exclaims that, lack of such sensitivity accounted for the problems and failures of many projects. This observation is premised on the positive attributes of involving the local people's knowledge in tackling community problems. For instance Chiome and 
Gambahaya (2000:65) acknowledge that, "the manifestation of an empowered community entails the visible use of their indigenous knowledge in resolving their own problems". This can be substantiated by a significant portion of the respondents, who in the focus group discussions remarked that, "...the reason why this project was moving slowly is because of the implementing agent's reluctance to fully and effectively consider all stakeholders as equal partners in this particular project".

Some were heard in focus group discussions exclaiming that, "...if they could consider us as partners we would even go on to the extent of providing our resources such as cowdrawn carts and labor, and it would be cheaper...".

These remarks complement Farm Africa's (1996) observation that, effective participation yields such advantages as reduced costs and efficiency, higher productivity and ultimately sustainability and self reliance. Unfortunately, these advantages seem to have been missed due to this unwarranted disregard of the local people. The researcher observes that, this demonstrates the indispensible fact that, if communities are accorded a chance to provide their skills in community development endeavors, they would eventually become empowered to efficiently progress with future development initiatives even in the absence of donors, which is a product of dedication to participation. It logically stands therefore to argue that, the principle of equal partnership is the root for effective community mobilization and participation since it gives the community exposure to be responsible and this aid in eliminating the barrier of lack of transparency or trust.

Favoritism. This is qualified by O'Donnell (1992:12) who argues that, "discriminatory selection of participants is a recipe for the demise of efforts to mobilize communities to effectively participate in development projects". This could be a product of different aspirations among the community members. This was noticeable in the composition of women and man who participated in this project. Males constituted $66 \%$ whilst there was $34 \%$ for females. This account for why some women in focus group discussions decried over selection of male representatives especially in the community task team. On the same note, the tribal variations are also indicative of the favouritism in selection since the Karanga were the dominant tribal group both among the participants and in the VIDCO. Even the findings on participation on ethnic basis, the Karanga constituted 56\%, Ndau $29 \%$ and Zezuru $15 \%$. One man confirmed in the interviews on the question of challenges that, "...in most cases it was always the Karanga and no opportunity for other Ndau and Zezuru people. There was favor in the appointments since this was mainly done by Care alone...".

It is the researcher's opinion that, effective community participation in this context suffers from the consequent apathy due to negative attitudes developed by the relegated groups. This is complemented by Mason etal (2000:19) who notes that, "...the disgruntlement does not only manifest in droopiness or reluctance to participate, it sometimes degenerates into physical protestations that are not only detrimental to the community project, but even to the development agents".

On the same note, some women also decried their relegation from influential positions,

"...by some overzealous men who are still mentally imprisoned and unenlightened since they still adhere to the archaic patriarchal ideology of male superiority and female subordination".

This was uttered by one lady teacher from the community but was shared by many women who participated in the focus group discussions. This deliberation did not only disclose that the selection criteria was gendered, but, culminated in the stifling of the efforts to incorporate women into participation. This is qualified by Oakley's (1992) observation that, women in developing communities have suffered a double tragedy in that culturally they have been relegated to inferiority in terms of status, and in development they are also marginalized on the wrong basis of assumed lack of knowledge. Apart from the noticeable fact that there was no consideration of the principle of inclusion which Maser (1998) considers to be fundamental, the researcher therefore notes that, these consequences could have provoked the departure from Women in Development Approach and Women and Development Approach to Gender and Development Approach, because the first two approaches were characteristically based on selectivity and connoted a positive 
discrimination against women in favor of men (Maser, 1998:23). The fact that the efforts to include the perceived disenfranchised group in this case was strangled by selectivity, hints on the need to observe the participatory principle of inclusion both in spirit and in practice, if full participation of the community is to be feasible.

Bureaucracy and Political Influences. It should be noted that bureaucracy and political influence has got an effect of rendering the local people passive recipients of development projects (Makumbe, 1998). In this context the agent was too bureaucratic as well as the RDC to such an extent that the subsequent deliberations seized to be freely open to the local villagers. If Berrenman's (2004) submission that "where there is bureaucracy there is autocracy", is to go by, then it is compelling to argue that, this bureaucratic nature of the development agencies results in a top-down type of approach since the decision making power would be a prerogative of just a few individuals yet it affects the whole community. This is supported by Mathur (2004) who attests that, bureaucrats have contempt for the capabilities of the poor to determine needs and direct development. Perhaps, this is because Thompson (1995) revealed that the state on one hand is too middle-class and the NGOs on the other hand are upper-class and middle-class, that is, the functionaries working in these agencies are drawn mainly from the urban class. This makes their lifestyles, values and inspirations to clash with their assigned tasks and the rural poor class. Berrenman (1994) opines that, lacking adequate training for effective mobilization of these poor, they feel they know what is best for their clienteles, a scenario which directly contradicts the PeopleCentered Development approach's advocating against assuming the grassroots as inexperienced and passive recipients of externally designed programmes. In such a context, the agencies' approach is likely to be patronizing and authoritarian. This was confirmed by various sentiments from respondents who were quick to blame everything on the way in which politics was a major problem to their zeal to participate. One man was heard saying that, "...the problem was that everything was done behind closed doors because it would take time to get information about the next activity and the reason was that they were waiting approval from the RDC which is the government. In the RDC again you would hear that the District Administrator is not available or the Councilor so no one can sign the papers. Besides, everything was done under the banner of ZANU PF as if these were elections. So some people were either afraid of not participating or participating".

Surely, if such politicization continues unabated, it would be a dream to envisage effective participation especially if fear is the force behind the mobilization of the community as on women confirmed that, "... if you disagree you will be punished by the ZANU PF people since they will accuse you sabotaging their efforts to build the nation and that you are an MDC supporter".

This view is supported by De Wit et al (1992:45) who attest that, the social structures in targeted areas are such that information is channeled through local leaders who are often political patrons or professional middle-men, thus the rural poor remain silent and the local leaders make decisions about important issues also affecting the former without the former's involvement. Ticconi and Tisdell (1992:275) see participatory approach as a collision path between the state, NGOs and the village social arrangements. These often have different and contradictory interests in that for instance, the state through its agents wants political mileage; the NGO wants more funding from its donors and the village wants community development. The need for power sharing is often resented by those wielding it. Consequently, participation would be supported half-heartedly (De Wit et al, 1992:53).

As a corollary, the poor tend to reject participation in the project if they believe their contributions will be insignificant as was the case in this project as evidenced in the variations in on the number of participants at various stages of the project cycle as indicated in figure 4 above. This perhaps accounts for why $69 \%$ indicated that the participation was involuntary generally because they were afraid of the political backlash if they do not participate since the whole project was politicized. Only $31 \%$ confirmed it was voluntary and they indicated that they were proactive from the outset o the project. This only goes a long way in supporting Cooke and Kothari's (2001) argument that, participation is secondary and 
often incongruent with the political and organizational imperatives of conventionally managed projects.

The influence of Project Objectives and Activities on Community Participation. One of the main activities of this project was community mobilization and maximum community participation since it was said to be a community based project. This mobilization was done in different activities and seems to have been based on the project's major objective which was stated as "To develop an effective and appropriate methodology to initiate and implement (by community), small dam rehabilitation in Mushagashe. This demonstrates the implementing agent's commitment to ensuring the massive involvement of the community in efforts towards achieving the stated objective. It shows that the community was expected to be at the fore of 'initiating' and 'implementing' whatever was necessary for the fruition of the project. This seemed as if the community was to partake in the whole project. Nevertheless, this seeming commitment emerged to be theoretical than it would be practical if cross-examined against the findings. The research confirmed and affirmed Chambers (1992) and Cordillo's (2001) observation that, much of literature on community participation is project documentation by international and local NGOs on particular projects they support, which does not reflect the real activities on the ground. The research suggests that, they just purport the prevalence of such participation on paper as a matter of record to appease their donors such that they secure long term funding. This assumption is based on the absence of a genuine reason by the NGO for not ensuring that what they write as their programme objectives and activities inform practice. This was also solidified by respondents from semi-structured interviews who happened to be representatives of Care; one field officer Julius confessed that, "...we just draft these programmes without due input of the local people because it serves no purpose to consult them on project proposals on which they are logistically unknowledgeable of".

Another one stated that, "...yes we do value community participation, but for things to move on it's not always the case that these local people should take part, it is not feasible". The research revealed that, these sentiments are just but a mere reflection of the extent to which it is a vivid and valid to allege that NGOs are hypocritical in their undertakings in that, on paper they claim to establish mechanisms that support positive and effective community engagement yet on the ground the playbook changes.

\section{CONCLUSION}

It is indisputably clear from the research that the deteriorating socio-economic conditions of communities can be improved if they themselves actively participate in the very development processes meant to be their remedy. However, it should be noted that, to ensure effective cooperation and involvement of the community in the development process in a more practical sense, has proven to be a sheer paradox, which has been predominantly purported and sustained through the use of the word 'participation', which nevertheless has also shown to be a catchphrase of many development agents. This study has demonstrated that community participation can only be successful if organizations recognize the inherent structural limitations and opportunities for effective institutionalization of community participation especially the elimination of the barriers identified in the research such as intra group conflicts, domineering development agent, preferential treatment, bureaucracy and politicizing development. The fruition of effective community participation rests on the recognition of the functionality of the principles of participatory approach which are; inclusion; equal partnership; transparency; sharing power; sharing responsibility; empowerment and cooperation. The cogency of this observation can be validated by an appreciation of the positive correlation of these principles with the various setbacks to effective community participation as established by the research. The fact that the People-Centered Approach to development celebrates participation of the grassroots in all stages of the community development cycle deductively implies that, exclusion of the grassroots is tantamount to limited cooperation of the grassroots which implies limited participation. Hence the rationale for assessing community participation in rural development projects as was the 
preoccupation of this particular research is tenable, especially if the effective involvement, mobilization and participation of the community for real empowerment are to be feasible. Therefore, there should be operationalization of the principles of the participatory approach in order to eliminate the various ways in which effective community participation can be constrained. More importantly, the community should be given an opportunity to identify its own problem, design its own solutions, implement the solutions and monitor and evaluate every activity on an ongoing basis without undue interference of any sort. This would go a long way in ensuring a departure from the conceptualization of participation as tokenism or a mere formality.

\section{REFERENCES}

[1] Arnstein, S.R, 1969. "A Ladder of Citizen Participation", JAIP, Vol.35, No. 4, July 1969, pp. 216-224.

[2] Awori, A. et al. 1996. A Model for Sustainable Livelihood and Natural Resources Management in Africa. Nairobi: Kenya Energy and Environment Organizations.

[3] Berrenman, G.D. 1994. Anthropology, Development and Public Policy. Kirtipur. Tribhunvan University Press.

[4] Bortei-Doku, E. 1991. "People's participation projects: Ghana", Africa Quarterly, Vol. 19, No. 2, pp. 102-115.

[5] Brohman, J. 1996. "Universalism, Eurocentricism and Ideological Bias in Development Studies: From Modernization to Neo-liberalism", Third Word Quarterly, Vol. 16, No. 1, pp.90-103.

[6] Brown, C .J. 2000, "A Model of the Facilitation of Community Participation in the Scoping of Projects" in F. Theron, A. Van Roo yen and J. Van Baalen (eds) Good Governance for People: Policy and Management, Bellville: School of Public Management and Planning, University of Stellenbosch.

[6] Catanese, A. J. 1984. The Politics of Planning and Development. London: Sage.

[7] Cernea, M.M, 1994. Sociological Knowledge for Development Projects, in Putting People First: Sociological Variables in Rural Development. London: Oxford University Press.

[8] Chambers, R. 1992. Rural Development: Putting the Last First. London. Prentice Hall.

[9] Chambers, R. 1998. Rural Development: Putting the Last First, Longman London.

[10] Chiome, G and Gambahaya, T. 2000. Culture and Development. Gweru. Mambo Press.

[11] Coetzee, J. 2001. Modernization Theory, (eds) Coetzee, J; Graaff, J; Hendricks, F. and Wood, G. 2001. Development Theory, Policy and Practice. South Africa. Oxford University Press.

[12] Cooke, B. and Kothari, U. 2001. Participation: The New Tyranny? New York: Zed Books.

[13] Cordillo, S. 2001. Community Development and Beyond. London. Irwin.

[14] De Wit, J, et al. 1992. "Community Participation in Low-Housing Policies: Potential or Paradox", Community Development Journal, Vol. 28, No. 1.

[15] Dennis, M, 1997. Ineffability in the Lao Tzu: Taming of the dragon, Journal of Chinese Philosophy, Vol. 4, No. 3, pp357-382.

[16] Eade, D and Williams, J, 1995. "The Oxfam Handbook of Development", in The Focus on Gender, Vol. 2, No. 1, pp. 98-107.

[17] Eade, D, 2000. Capacity Building Approach to People Centered Development. London: Oxford University Press.

[18] Farm Africa, 1996. Konso Integrated Development Project. Annual Report. From Modernization to Neo-liberalism. Third World Quarterly, Vol. 16, No. 1.

[19] Fortmann,L. and Nabane,N.1992 "The fruits of their labour: gender,property and trees in Mhondoro District",Occasional paper series-NRM6/1992,Harare,Centre for Aplied Social Sciences Publications, University of Zimbabwe. 
[20] Gukurume S, Nhodo L, 2010. Conservation Farming and the Food Security-. Insecurity Matrix in Zimbabwe: A case of ward 21 Chivi Rural. Journal of Sustainable Development in Africa, Vol.17, No.7.

[21] IUCN,2005.Gender mainstreaming in Wetland ecosystems and natural resource management:Bridging the gap: Gender and Conservation in Zimbabwe projects,IUCN.

[22] Howard, F, 1998. Community Development: A Historical Perspective. London: Longman.

[23] Kanyenze, D, 2004. Zimbabwe Economic Policies: 1980-1996. Harare: Weaver Press.

[24] Kaufman, M. and Alfonso, H.D. 1997. Community Power and Grassroots Democracy: The Transformation of Social Life. New Jersey: Zed Books.

[25] Kottack, P.C. 1996. Exploring Human Diversity: An Anthropological Perspective. London: Rutledge.

[26] Makumbe, J. M.W. 1998. Participatory Development: The Case of Zimbabwe. Harare: UZ Publications.

[27] Maser, C, 1997. Sustainable Community Development, Principles and Concepts. Chicago: St Lucia Press.

[28] Mason, B, 2003. Community Participation and Empowerment. London: Routledge.

[29] Mason, B. and McNulty, D. 2000. Community Participation for Empowerment: A Manual for Development Agents. Care international.

[30] Matowanyika, S, 1998. Participation, Power and Development. Harare: Sapes.

[31] Mosse, D, 1998. People's Knowledge, Participation and Patronage: Operations and Representations in rural Development. London: McMillan.

[32] Muther, H.M, 2004. The Human Dimension of Development: Perspectives from Anthropology. New Delhi: Concept Publishers.

[33] O'Donnell, A, 1992. Sociology of Community Development. Delhi: Nelson Publishers.

[34] Oakley, P and Marsden, D, 1994. Approaches to Participation in Rural Development. Geneva, ILO.

[35] Oakley, P. 1998. Projects with People: The Practice of Participation in Development. Geneva. International Labor Office.

[36] Rahman, M.D.A 1993. People's Self-Development: Perspectives on Participatory Action Research, A Journal through experience. London and New Jersey: Zed Books.

[37] Rahnema, M. 1997. "Participation", in The Development Dictionary. Johannesburg: Witwatersrand University Press.

[38] Shaw, T.M. 1990. "Popular Participation in Non-government Structures in Africa: Implications for Democratic Development", Africa Today, $3^{\text {rd }}$ Quarterly.

[39] Steifel, M. and Wolfe, M. 1994. A Voice of the Excluded, Popular Participation in Development: Utopia or Necessity? London: Zed Books

[40] Thompson J. (1995). Participatory Approaches in Government Bureaucracies: Facilitating a Process of Institutional Change, in World Development. Vol. 23, No. 9. pp 1521-1547.

[41] Ticconi, L. and Tisdell, C. 1992. "Rural Development in LDCs: Appraisal, Participation and Sustainability", in The Journal of Public Administration and Development, Vol. 12, No. 3.

[42] UNDP, "Annual Human Development Report", 1998. Oxford: UNDP.

[43] Wilcox, B, 1996. Inspecting Schools: Holding Schools to Account and Helping Schools to Improve. Buckingham: Open University Press.

[44] Winder, D. 1981. Studies in Rural Development. Manchester: Manchester Papers. 